\title{
Are cancer helplines effective in supporting caregivers? A systematic review
}

\author{
Leila Heckel $^{1}$ - Natalie L. Heynsbergh ${ }^{1}$ (D) Patricia M. Livingston ${ }^{1}$ \\ Received: 14 December 2018 / Accepted: 7 April 2019 / Published online: 16 May 2019 \\ (C) The Author(s) 2019
}

\begin{abstract}
Purpose The aims of this systematic review were to summarize the profile of caregivers accessing cancer helplines, to evaluate caregiver satisfaction with the helpline service, and to review the evidence base of intervention studies testing the efficacy of community-based cancer helplines in improving caregiver health and well-being.

Methods Four electronic databases (Medline, CINAHL, PsychINFO, and EMBASE) were systematically searched to identify relevant literature, including all articles published in English until May 2018. Reference lists of accepted papers were reviewed for the inclusion of additional potentially relevant articles, gray literature was excluded.

Results Forty-five publications met the inclusion criteria for this review. Forty-one papers reported on the proportion of caregivers accessing cancer helplines. Twenty-six studies described demographic and clinical characteristics of caregivers and eight reported on call characteristics. Reasons for contacting the service were stated in 21 studies and caregiver satisfaction with the helpline service was assessed in 12 articles. Fourteen studies investigated specific topics of interest (e.g., prevalence of sleep problems, distress screening, or clinical trial participation). Two randomized controlled trials examined the efficacy of cancer helplines in improving caregiver outcomes, with findings showing interventions to be effective in reducing distress and unmet needs, and in increasing positive adjustment.

Conclusions There is limited scientific evidence regarding the efficacy of cancer helplines to improve caregivers' health and wellbeing. More intervention studies are needed to examine the benefits of cancer helplines to this study population to ensure structured referral pathways can be established.
\end{abstract}

Keywords Cancer $\cdot$ Cancer information and support services $\cdot$ Caregiver $\cdot$ Helpline $\cdot$ Oncology $\cdot$ Systematic review

\section{Introduction}

Informal caregivers are required to provide holistic support to cancer patients throughout the cancer trajectory [1]. This is primarily attributable to changes in the administration of cancer treatments with a shift from cost-intensive inpatient services to outpatient clinics [2]. Secondly, cancer is now recognized as a chronic condition due to increased survivorship

Electronic supplementary material The online version of this article (https://doi.org/10.1007/s00520-019-04807-z) contains supplementary material, which is available to authorized users.

Natalie L. Heynsbergh

n.heynsbergh@deakin.edu.au

1 Faculty of Health, School of Nursing and Midwifery, Deakin University, Geelong, VIC 3220, Australia rates resulting from advances in diagnostic procedures and therapeutic agents [3]. Subsequently, more people now live with this complex chronic disease which requires ongoing monitoring and care [4].

In their role as informal caregivers, family members and friends take on a multitude of responsibilities and caregiving tasks, however, in many instances, with minimal support and without formal training [5]. During their journey, caregivers experience various unmet needs, significant burden and anxiety [6-9], impacting adversely on their own physical and mental health [10].

Intervention studies have been designed and tested in an effort to support informal caregivers in their caregiving role [11-13]. While these trials showed small to moderate effects, suggesting only limited efficacy on caregiver outcomes, they did produce significant improvements in caregiver burden, coping behavior, quality of life, and self-efficacy [1]. The main drawbacks to supportive care 
interventions are firstly the costs of having them implemented in the health care setting as most interventions are delivered by qualified professionals. Secondly, the time requirement makes it difficult to have them integrated into caregivers' busy time schedules, and thirdly, the accessibility with limited availability to those living in nonmetropolitan areas [6, 14]. However, caregivers require continuous access to support services in order to obtain adequate knowledge and skills for each phase of the cancer care trajectory. Therefore, it is important to explore other potentially feasible solutions for the delivery of cancer information and support to caregivers, such as the role of community-based support services.

In 1975, the National Cancer Institute in the USA established the first Cancer Information Service (CIS), providing high-quality cancer information via telephone to families affected by cancer, health professionals, and the public [15]. The successful implementation of this service inspired many other community-based cancer organizations to develop similar CIS programs worldwide, and in 1996 the International Cancer Information Service Group (ICISG) was established [16]. At present, the ICISG comprises 30 member countries with a network of approximately 50 cancer information services, its main goal being the provision of standards and resources for the delivery of high-quality cancer information [16]. Cancer Information Services are operated by specially trained and highly qualified staff who provide individualized information, cancer-related emotional and practical support, and referrals to follow-up care [17]. Hours of operation vary across services and individuals are required to self-initiate contact via toll-free numbers or the cost of a local call $[15,17,18]$.

While cancer helpline users have reported high levels of satisfaction regarding the delivery of cancer information and support $[19,20]$, less is known about the actual ability of these telephone services to change caller health and well-being. A review of the literature examining the benefits of cancer helplines for people diagnosed with cancer showed a lack of scientific evidence with only three methodological robust studies evaluating the efficacy of cancer helplines in improving patient outcomes [21]. The studies under review revealed mixed results regarding improvements in self-efficacy and psychological distress ranging from no changes to significant reductions in mood swings and feelings of loneliness in individuals diagnosed with cancer. The authors highlighted not only the need for more rigorous efficacy trials to better understand the value of helplines in delivering information and support to cancer patients and survivors but also the importance of evaluating the benefits of cancer helplines to cancer caregivers, given their substantial involvement in patient care [21].
This systematic review aimed to describe the literature reporting on:

a) caregiver access to community-based cancer helplines including the following:

- proportion of caregivers accessing the service

- demographic and clinical characteristics of caregivers

- call characteristics (e.g., patterns of use, source of referral, lengths of calls)

- reasons for calling

b) User satisfaction

- level of satisfaction with the helpline service

- acceptability and impact of the helpline service

c) The efficacy of community-based cancer helplines in improving psycho-social outcomes of caregivers, e.g.:

- psychological distress, caregiver burden, unmet needs

- self-efficacy, empowerment, involvement in decisionmaking

\section{Methods}

This systematic review was conducted in accordance with the PRISMA statement [22]. A narrative synthesis approach was used due to the heterogeneity of study designs and the inclusion of descriptive as well as intervention research.

\section{Inclusion and exclusion criteria}

The PICO framework [23] was used to develop a systematic search strategy:

Participants: Adult caregivers of adult cancer patients (any cancer type or disease stage). Studies only focusing on cancer patients were excluded.

Interventions: Community-based cancer telephone services focusing on improving caregiver health and wellbeing; studies including cancer dyads (patient and caregiver together) if caregiver data was reported separately. Control groups: To fully address the research question, randomized controlled trials, single-arm trials (pre-post trials), and studies reporting on the characteristics of caregivers and their satisfaction with cancer helplines were accepted.

Outcomes: There were no restrictions on the type of outcomes for the efficacy trials but studies should target caregiver needs and well-being. 
To allow for comparisons with Clinton-McHarg et al. [21] findings, similar inclusion and exclusion criteria were applied. Articles were excluded if they were not published in English, duplicates, not of original research, not a journal article, or not relevant to cancer caregivers. Studies were excluded if they described a telephone-based service which was (a) not community delivered (e.g., hospital hotline to support patients and their families admitted to this health service); (b) community delivered but: focused on cancer screening/prevention (e.g., smoking quitlines), did not address cancer-related issues (e.g., crisis lines for other diseases), examined the delivery of psychological therapies/services (e.g., cognitive behavioral therapy, psychological counseling services), or provided peer support (e.g., telephone support delivered by another cancer caregiver).

\section{Search strategy and study selection}

Prior to conducting this systematic review, protocol registries PROSPERO, Cochrane, and Joanna Briggs were initially searched and no existing systematic review protocols on this particular topic were found. A systematic and comprehensive search of peer-reviewed literature was conducted in four electronic databases: MEDLINE complete, CINAHL complete, PsychINFO, and EMBASE and included all articles published until 24 May 2018. In addition, snowball searching for citations and references of key articles was performed to identify potentially eligible papers. Gray literature was excluded as it often reports on preliminary findings which are inconsistent with final results; with changes in outcomes from conference abstract to full-length publication in up to $41 \%$ of cases [24].

The literature search was conducted using the following key search terms:

Cancer and (caregiver* or carer* or spouse* or partner* or famil* or "significant other*" or caller*) and ("cancer telephone support" or helpline or "help line" or hotline or "hot line" or CIS or "telephone counsel*ing" or "telephone support" or "telephone information service*" or "telephone service*" or "cancer information and support" or "information service*"). These terms were searched within the title, abstract, and keywords. Subject headings (e.g., MeSH terms) for each database were also included in the search.

\section{Review process}

An initial assessment against the inclusion criteria was performed by LH for all identified titles, abstracts, and full-text articles. Studies not meeting inclusion criteria were excluded and full text of potentially relevant manuscripts was subsequently reviewed for eligibility by $\mathrm{LH}$ and $\mathrm{NH}$. Discrepancies among reviewers were discussed until $100 \%$ agreement was reached.

\section{Data extraction}

Data for publications meeting the inclusion criteria for efficacy studies (randomized controlled trials) and single arm studies were extracted into a coding sheet and included: authors, year of publication, country, participants and sample size, study design, description of the telephone intervention, pre/ post assessments, primary/secondary outcome measures, and key results.

Data for publications describing caregiver helpline utilization and satisfaction, and for those reporting on cross-sectional analyses were extracted into a separate coding sheet and included: authors, year of publication, country, sample size (percentage of caregivers contacting the service), characteristics of callers (caregivers), topics discussed/reasons for calling, user satisfaction, impact, and outcome (see Online Resource 1).

\section{Risk of bias assessment}

Randomized controlled trials were assessed for risk of bias against the Cochrane Handbook for Systematic Reviews of Interventions [25] and included random sequence generation, concealment of allocation sequence, blinding of participants/ personnel/outcome assessors, missing outcome data, and selective reporting of results. An independent review for study bias was conducted by reviewers $(\mathrm{LH}, \mathrm{NH})$ and discrepancies in scores were resolved through discussion.

\section{Results}

\section{Systematic database search}

The systematic database search yielded a total of 3203 publications, from which 1114 duplicates were removed; 32 additional papers were identified through other sources. After title and abstract screening 151 full-text copies were obtained and screened against inclusion criteria. Of those, 106 manuscripts were excluded as they did not report on caregivers (or failed to present caregiver data separately) or described a telephone service other than CIS. A total of 45 papers were included in this systematic review (Fig. 1).

\section{Summary of included studies}

Table 1 provides an overview of the 45 included research articles. Studies were conducted in the USA $(n=19)$, Australia $(n=14)$, UK $(n=7)$, Netherlands $(n=2)$, Canada $(n=1)$, Nigeria $(n=1)$, and Serbia $(n=1)$. Forty-one papers reported on the proportion of caregivers accessing cancer helplines [20, 26-64, 68], demographic information was outlined in 22 articles [26, 31, 32, 37, 38, 40-42, 44, 46, 49, 51-53, 55-58, 61, 65-67], call characteristics were described 


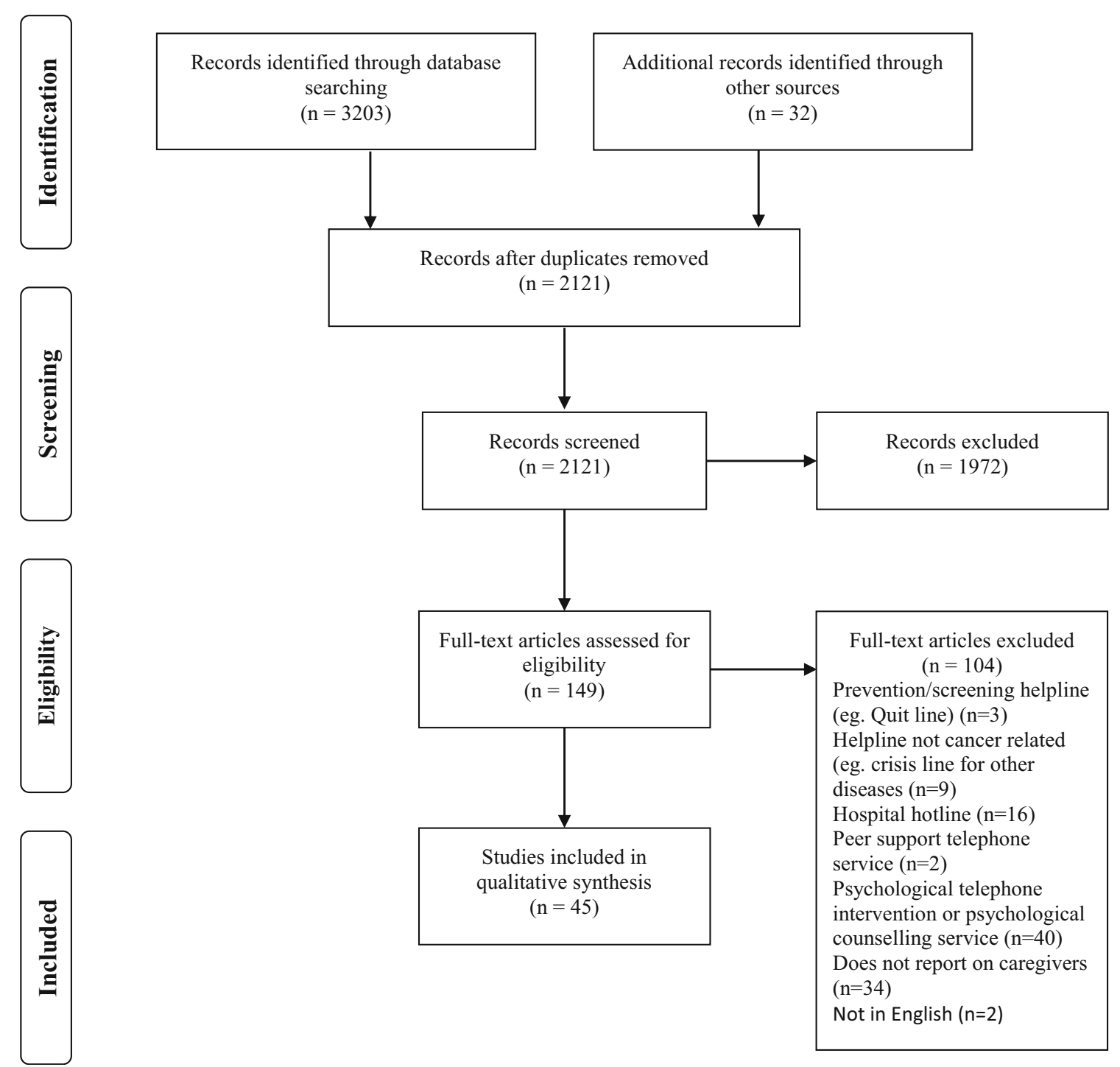

Fig. 1 PRISMA flowchart of systematic literature search

in eight studies [30, 38, 41, 43, 44, 52, 61, 66], four papers reported on caregivers' clinical presentation [32, 38, 43, 66], and reasons for calling the helpline were stated in 21 articles $[26,30,33,35,38,40-42,44,49,51-55,58,61,62,64,66$, 68]. Fourteen publications studied caregivers who contacted cancer helplines to answer a specific research question (e.g., prevalence of sleep problems in caregivers) $[28-32,38,40$, $43,47,53,58,61,62,66]$ and 12 papers informed about caregivers' level of satisfaction with the helpline service [20, $26,33,35,37,46,48,56,60,63,64,66]$. A comprehensive description of the 42 manuscripts reporting on caregivers' access to and satisfaction with community-based cancer helplines, including study design and major findings is available for each individual study at Online Resource 1 . Two randomized controlled trials presented findings on the efficacy of cancer helpline interventions in improving caregiver outcomes [65, 69], and one single-arm analysis [66], which was part of the two-arm randomized controlled trial [65], reporting on changes in levels of distress and unmet needs as a result of the intervention (both were included in this review, but methods and findings are presented as one study).

\section{Summary of efficacy studies}

\section{Risk of bias}

Methodological rigor of the two randomized controlled trials $[65,69]$ was high, with both demonstrating low levels of bias (Table 2).

\section{Study design, content, and efficacy of interventions}

Table 3 provides a summary of the two efficacy studies included in the review. The randomized controlled trial conducted by Chambers et al. [69] comprised 354 cancer patients and 336 caregivers who had contacted community-based cancer 
Table 1 Summary of research articles reporting on caregivers accessing community-based cancer helplines $(n=45)$

\begin{tabular}{|c|c|c|c|}
\hline & Number of papers & References & Results \\
\hline Country of origin & 45 & $20,26-69$ & $\begin{array}{l}\text { The greatest proportion of studies were conducted in } \\
\text { the USA ( } 42 \%) \text {, followed by Australia }(31 \%) \text {, UK } \\
(16 \%) \text {, Netherlands ( } 4 \%) \text {, Canada }(2 \%) \text {, Serbia } \\
(2 \%) \text {, Nigeria }(2 \%) \text {. }\end{array}$ \\
\hline $\begin{array}{l}\text { Proportion of caregiver } \\
\text { contacts }\end{array}$ & 41 & $20,26-64,68$ & $\begin{array}{l}\text { The overall proportion of caregivers contacting cancer } \\
\text { helplines ranged from } 14 \%-67 \% \text { (call audits - } \\
\text { caregivers: } 14 \%-47 \% \text {; cancer patients: } 12 \%-66 \% \text { ) }\end{array}$ \\
\hline Demographic characteristics & 22 & $\begin{array}{l}26,31,32,37,38,40-42,44,46,49 \\
51-53,55-58,61,65-67\end{array}$ & $\begin{array}{l}\text { The majority of caregivers were: middle-aged (40-60 } \\
\text { years), female, Caucasian, well educated, resided in } \\
\text { urban areas, the spouse/partner of the cancer patient, } \\
\text { lived in the same household with the patient. More } \\
\text { than one third came from middle to high socio } \\
\text { economic backgrounds, were high income earners, } \\
\text { and worked part- or fulltime. The majority were } \\
\text { caregivers of patients who were receiving active } \\
\text { cancer treatment; the most common cancers } \\
\text { enquired about were breast, prostate, colorectal, } \\
\text { lung, and melanomas. }\end{array}$ \\
\hline Call characteristics & 8 & $30,38,41,43,44,52,61,66$ & $\begin{array}{l}\text { Most caregivers were first time users, average call } \\
\text { duration was } 19 \text { min (range: 12-24min). Caregivers } \\
\text { most commonly found out about the helpline } \\
\text { through health professionals, CIS staff/events, } \\
\text { internet or the media. }\end{array}$ \\
\hline Clinical characteristics & 4 & $32,38,43,66$ & $\begin{array}{l}\text { One-third of caregivers were found to be distressed or } \\
\text { depressed and presented with a mean score of } 6 \text { on } \\
\text { the Distress Thermometer (range } 0-10 \text { ). }\end{array}$ \\
\hline Reasons for calling & 21 & $\begin{array}{c}26,30,33,35,38,40-42,44,49 \\
51-55,58,61,62,64,66,68\end{array}$ & $\begin{array}{l}\text { The most common reasons for calling were to receive } \\
\text { emotional/psychological support, to obtain cancer } \\
\text { information, to discuss issues related to treatment, } \\
\text { symptom management, prevention, diagnosis, and } \\
\text { possible causes. }\end{array}$ \\
\hline $\begin{array}{l}\text { Investigations with a specific } \\
\text { research focus (e.g. } \\
\text { qualitative or descriptive } \\
\text { studies) }\end{array}$ & 14 & $\begin{array}{l}28-32,38,40,43,47,53,58,61,62, \\
66\end{array}$ & $\begin{array}{l}\text { Various studies investigated caregivers' accessing the } \\
\text { helpline to answer a specific research question: } \\
\text { caregivers living alone compared to general public; } \\
\text { caregiver distress, unmet needs, reasons for calling } \\
\text { compared to cancer patients; age and gender } \\
\text { differences among caregivers; caregivers use of the } \\
\text { internet to obtain cancer information; clinical trials } \\
\text { discussion by caregivers; distress thermometer } \\
\text { administration to caregivers; prevalence of insomnia } \\
\text { in caregivers. }\end{array}$ \\
\hline Satisfaction & 12 & $\begin{array}{l}20,26,33,35,37,46,48,56,60,63 \\
\quad 64,66\end{array}$ & $\begin{array}{l}\text { Caregivers reported high levels of satisfaction } \\
(83 \%-96 \%) \text { : expectations were met or exceeded and } \\
\text { CIS staff was rated very positively; caregivers } \\
\text { reported increased cancer knowledge, enhanced } \\
\text { communication with healthcare teams, and } \\
\text { improved decision making. }\end{array}$ \\
\hline $\begin{array}{l}\text { Efficacy of intervention } \\
\text { studies in improving } \\
\text { caregiver outcomes }\end{array}$ & 3 & $65,66,69$ & $\begin{array}{l}\text { Two randomized controlled trials focusing on } \\
\text { caregiver burden, unmet needs, self-empowerment, } \\
\text { distress and post-traumatic growth. Results showed } \\
\text { reductions in levels of distress and unmet needs, and } \\
\text { an increase in positive adjustment. } \\
\text { One single-arm analysis focusing on changes in } \\
\text { caregivers' level of distress/impact of distress on } \\
\text { daily life, and unmet needs. Results showed } \\
\text { significant reductions for all outcome variables. }\end{array}$ \\
\hline
\end{tabular}


Table 2 Risk of bias assessment for included randomized controlled trials

\begin{tabular}{cllllll}
\hline Authors, year & $\begin{array}{l}\text { Random } \\
\text { sequence } \\
\text { generation }\end{array}$ & $\begin{array}{l}\text { Allocation } \\
\text { concealment }\end{array}$ & $\begin{array}{l}\text { Blinding of } \\
\text { personnel, } \\
\text { participants }\end{array}$ & $\begin{array}{l}\text { Blinding of } \\
\text { outcome } \\
\text { assessors }\end{array}$ & $\begin{array}{l}\text { Missing } \\
\text { outcome } \\
\text { data }\end{array}$ & $\begin{array}{l}\text { Selective } \\
\text { outcome } \\
\text { reporting }\end{array}$ \\
\hline $\begin{array}{c}\text { Chambers et } \\
\text { al. 2014 [69] }\end{array}$ & L & L & L & L & L & L \\
$\begin{array}{c}\text { Heckel et al. } \\
2018[65]\end{array}$ & L & L & L & L & L & L \\
\hline
\end{tabular}

helplines (Queensland and New South Wales, Australia) for support and had a distress score of $\geq 4$ on the distress thermometer (range $0-10$ ). The aim of the study was to compare the efficacy of two telephone-delivered interventions in reducing psychological and cancer-specific distress and improving positive adjustment in both the patient and the caregiver. Outcome measures were assessed at baseline, 3, 6, and 12 months post-recruitment. The two study arms comprised a single session of self-management intervention provided by a helpline nurse and a five-session cognitive behavioral intervention delivered by a psychologist (median session length $46 \mathrm{~min}, 49 \mathrm{~min}$, respectively). Participants in the brief nurseled arm received feedback on their distress score, instructions on how to reduce stress, cancer information, psychoeducation, and a resource kit for psychological self-management. The latter contained instructions for managing stress, problemsolving strategies related to cancer issues, educational material to promote a healthy lifestyle, advice on how to reduce the risk of isolation, and an audio $\mathrm{CD}$ with relaxation exercises. Participants in the psychologist-led arm received five counseling sessions of psychoeducation, strategies for coping, problem-solving and stress management, cognitive therapy, and the self-management resource kit. Findings related to caregiver outcomes showed a significant reduction in distress and an increase in positive adjustment from baseline to 12 months in both intervention arms. While the estimated sample size of 660 participants at baseline was achieved, the calculated attrition rate of $15 \%$ was only attained at the first follow-up assessment point; the problem of high retention rates was noted by the authors. The trial was funded by a grant from beyondblue, Cancer Australia (APP561701), Cancer Council Queensland and New South Wales.

The PROTECT multi-center, randomized controlled trial [65] comprised a sample size of 216 cancer patient/caregiver dyads. This study aimed to investigate the efficacy of a nurseled telephone outcall intervention $(n=108)$ compared to an attention control arm $(n=108)$ in reducing caregiver burden (primary outcome), depression and unmet needs, and to increase self-empowerment (secondary outcomes for both caregivers and patients). Assessment points were at baseline, 1 and 6 months post-intervention. Caregivers in the nurse-led outcall arm received a total of three telephone calls (5-10 days postrandomization, at 1 month, at 4 months) from an oncology nurse at two Australian community-based cancer helplines (South Australia, Victoria) (mean call duration, $22 \mathrm{~min}$ ). At each outcall, the helpline nurse administered the distress thermometer and offered referral to appropriate services for those with a distress score of $\geq 4$ and impact score of $\geq 3$. The nurse then raised six topics for discussion to address caregivers' unmet needs, these included psychological distress, health literacy, caregivers' own health, practical or financial concerns, or matters related to family life. Caregivers in the attention control group received a total of three outcalls from a researcher at the same time points as those in the nurse-led intervention group (mean call duration, $3 \mathrm{~min}$ ). Caregivers were given the cancer helpline number to self-initiate contact if needed. Those contacting the helpline would receive the usual support provided by the telephone service, not the tailored intervention. Findings showed that the intervention had no effect on caregiver burden but resulted in a significant reduction in the number of unmet needs from baseline to 1 month in the intervention arm compared to the attention control group. Very few caregivers $(6 \%)$ in the control arm contacted the helpline service. A subgroup analysis with caregivers at high risk of depression showed a significant intervention effect in the health literacy domain (having sufficient information to manage caregivers' health). The calculated sample size to be attained by the end of the trial (180 dyads, 90 in each arm) was achieved, however, there were substantial amounts of data lost to follow-up at each post-intervention assessment point which resulted in the study to be underpowered and this was noted as a limitation of the trial. This study was funded by the National Health and Medical Research Council (GNT1044400RM24525).

As part of the randomized controlled trial [65], a single-arm secondary analysis focused on the 108 caregivers in the nurseled intervention arm [66]. The aim of the analysis was to assess changes in caregivers' level of distress and impact of distress on daily life activities as measured by the helpline nurse at each of the three outcalls using the distress thermometer, as well as changes in unmet supportive care needs (six topics discussed) over the 4-month intervention period. Findings showed that caregiver levels of distress and impact of distress as well as the frequency of discussions related to psychological distress, health literacy, financial, and practical concerns decreased significantly over time. 


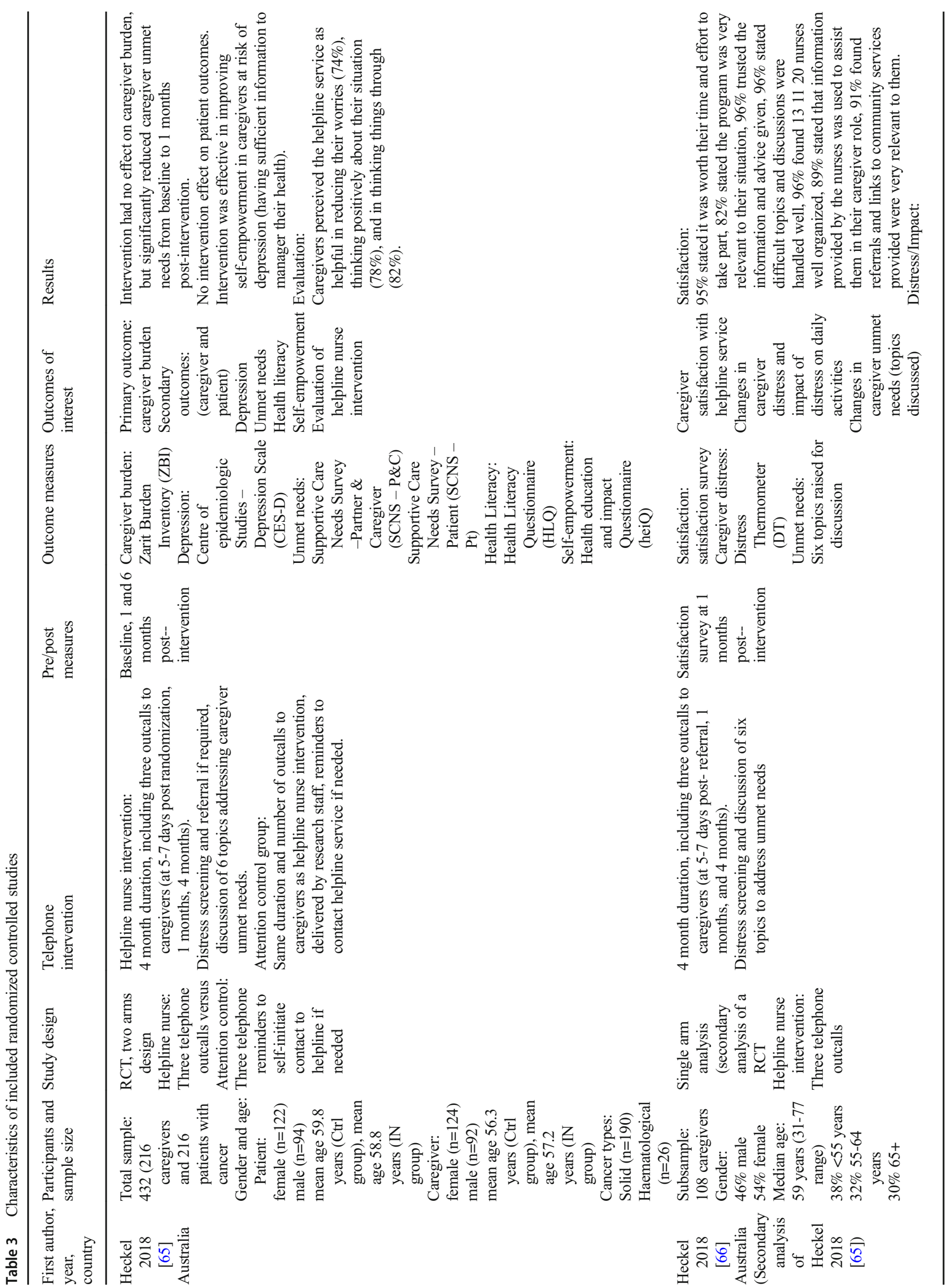




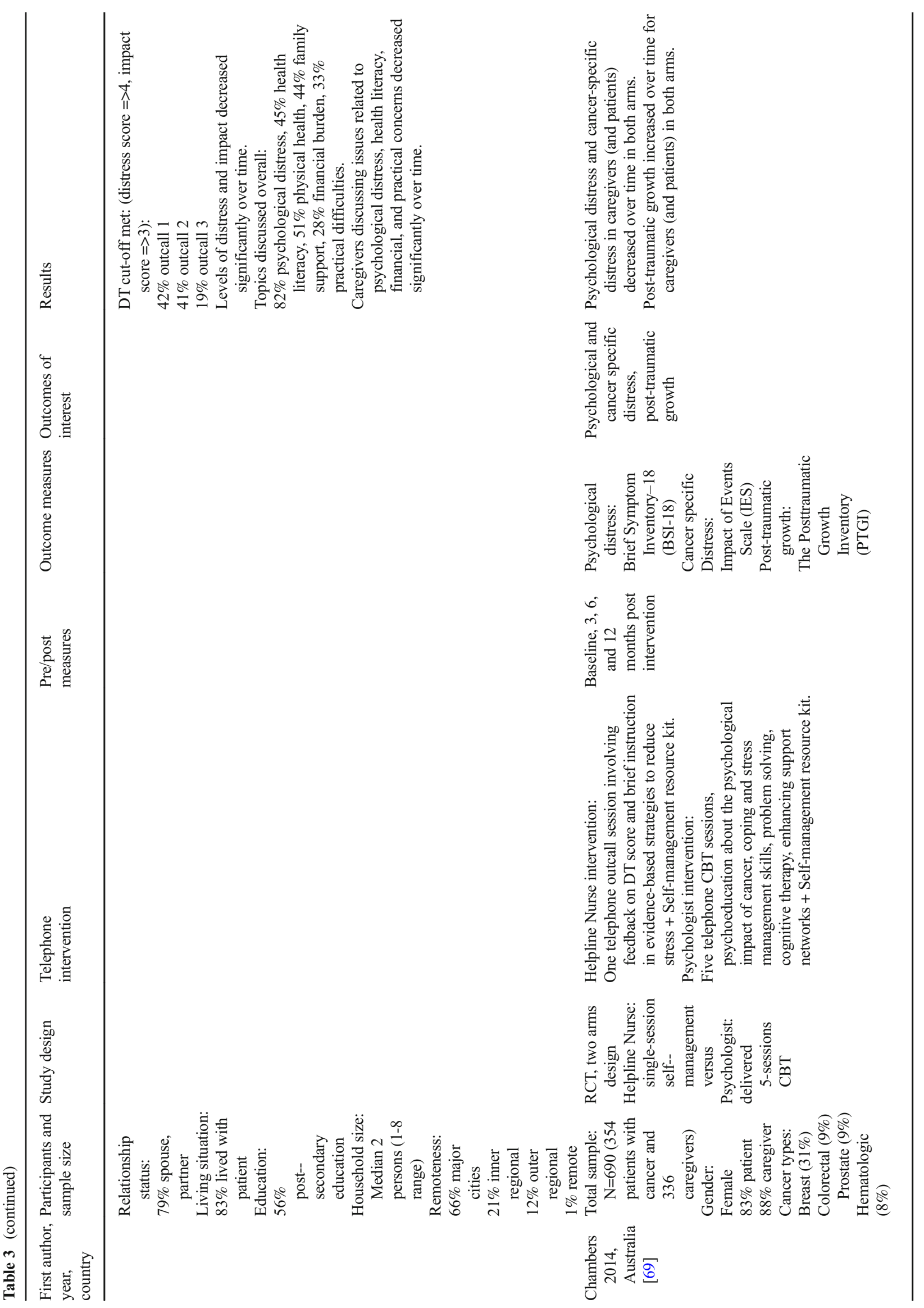




\section{Acceptability of the helpline intervention}

Acceptability of the helpline intervention was assessed through study recruitment rates and engagement with the intervention. Consent rates were not always clearly stated but could be calculated from data reported by the authors. The proportion of eligible callers recruited into the Chambers et al. [69] study was $22 \%$, which was similar to the PROTECT trial [65] which achieved a consent rate of $29 \%$. In terms of engagement, the single nurse-led intervention session in the Chambers' study [69] achieved a completion rate of $93 \%$, and $53 \%$ of participants completed all five of the psychologist-led sessions (median, 4 sessions). Completion rates for the three outcalls in the PROTECT trial [66] ranged from 88 to $95 \%$ for participants in the nurse-led outcall arm and from 90 to $94 \%$ in the attention control group.

\section{Satisfaction with and impact of the helpline intervention}

Participants' self-reported satisfaction and impact of the intervention was only assessed in one of the two randomized controlled trials $[65,66]$. Caregivers' experience with the helpline intervention was very positive. The helpline nurses who delivered the outcalls were viewed as confident and profession$\mathrm{al}$, and the information and advice they provided were rated as very beneficial and useful. The majority of caregivers stated that the intervention had a positive impact on their health and well-being, their understanding of cancer, and on developing a positive outlook on life.

\section{Discussion}

This review aimed to assess caregiver access to and satisfaction with community-based cancer helplines and to determine the efficacy of helpline interventions in improving caregiver health and well-being.

\section{Caregiver profile and level of satisfaction with the helpline service}

Studies reporting on call audits showed that the proportion of caregivers accessing cancer helplines ranged from 14 to $47 \%$, which was lower than that reported for cancer patients (12$66 \%$ ). The majority of caregivers were middle-aged or older, female, Caucasian, highly educated, and married (or in defacto relationships). The caregiver profile is similar to that reported for diagnosed patients/survivors accessing cancer helplines [21], which highlights the need for more detailed investigations into the reasons as to why caregivers and patients alike, who present with a different profile (e.g., younger, male, less educated) make less use of these services. Studies included in this review suggested the identification of existing 
barriers for accessing cancer helplines and investigations as to whether their needs are being met by other support services or networks [41]. Fennell et al. [38] reported that the Australian Cancer Council changed the name of their Cancer Council Helpline to "Cancer Council 131120 for Information and Support," removing the word "help" to increase male usage of this service as evaluations had revealed that users indicated a dislike for asking for help.

Most caregivers were first time users with a call duration of approximately $20 \mathrm{~min}$. Some studies reported that it was common for caregivers to initially request service and cancer information while the need for emotional support emerged later during the call $[30,51]$, highlighting the need for helpline operators to use probes to detect underlying psychological needs in caregivers when contacting the service at the very first time.

Further, the majority of caregivers contacted the helpline during active cancer treatment, most commonly requested emotional support, information on cancer treatment, and symptom management. Noteworthy, one-third were found to be distressed at the time of calling. It appears that caregivers have high emotional and information needs during the active treatment phase, a time that usually requires high caregiver involvement in the management of patient care in the home setting [1]. Studies have shown that caregivers are not adequately trained for such a complex role and support from the health care system is often lacking [5]. Findings of this review may suggest that cancer helplines have the capacity to compensate for the lack of support for caregivers by off-setting communication barriers between health professionals and families affected by cancer [16].

Caregivers valued the helpline service highly, which was demonstrated by high levels of satisfaction with the quality of information provided as well as with the communication skills of helpline operators who showed high levels of professionalism including sincerity, respect, and empathy, and reports on positive impacts on caregivers' lives such as enhanced communication with the healthcare team, increased cancer knowledge, and improved decision making. Similarly, the systematic review conducted by Clinton-McHarg et al. [21] revealed high levels of satisfaction and acceptability in cancer patients who contacted cancer helplines for support.

\section{Efficacy of intervention studies}

While findings in the literature overall indicate positive user experiences with cancer helplines, the actual benefits of these services on user outcomes are unclear. The systematic review conducted by Clinton-McHarg et al. [21] which evaluated the benefits of cancer helplines in the cancer patient population only found three intervention studies with strong methodological rigor, and findings of these trials provided limited evidence for the efficacy of helpline services in changing patient outcomes. This review only identified two randomized controlled trials testing the efficacy of cancer helpline interventions to enhance caregivers' health and well-being. The study by Chambers et al. [69] showed that both, the nurse-led and the psychologist-led intervention were effective in reducing distress and enhancing positive adjustment in caregivers. While the authors highlight the potential benefits of a brief, low-intensity nurse-led intervention; findings need to be interpreted cautiously as the study was conducted without the inclusion of a control group (e.g., no treatment/usual care group) and it is possible that the changes seen in both treatment arms were not entirely generated by the intervention. The PROTECT trial [65] revealed that the nursedelivered telephone outcall intervention did not demonstrate a significant effect on the primary outcome caregiver burden, and no differences between the two study arms were found for depression and self-empowerment. However, a greater reduction in unmet needs was observed in caregivers receiving the nurseled intervention compared to those in the attention control group. A secondary analysis [66] also showed significant changes in level of distress and unmet supportive care needs (topics discussed) over the trial period. A possible explanation for these findings may be that the six topics raised by the helpline nurses targeted caregivers' potential unmet needs which may have caused the significant reduction over the course of the intervention in this domain. In addition, low levels of burden and depression at baseline reported for most caregivers enrolled in the trial may have minimized the chances of detecting any changes over time, as a significant intervention effect in the health literacy domain was only detected in caregivers identified with increased risk of depression at baseline.

\section{Strengths and weaknesses of efficacy studies}

Methodological rigor was high with both randomized controlled trials showing low level of bias. Further, heterogeneity in both trial samples (including both male and female caregivers as well as a wide range of cancer types) allows findings to be applied to the broader cancer caregiver population. However, it is noteworthy that both studies were conducted in Australia, which may limit generalizability of outcomes to other countries due to possible variations in caregiver experiences, cancer helpline operations, and health care systems. The absence of a control group in the Chambers et al. study [69] weakened the evidence for the nurse-led intervention of its potential impact on caregiver health outcomes; however, the brief, one-session intervention in this trial may be more feasible and cost-effective in the helpline setting than the delivery of three outcalls [65].

\section{Study limitations}

This systematic review only included peer-reviewed publications that reported on caregiver access to cancer helplines; it 
might also be worthwhile to assess the benefits of cancer helplines on medical and allied health care professionals who contact these services to evaluate any impacts on service delivery in these settings. Further, only articles published in English were included in this review, which may have resulted in the exclusion of relevant literature from non-English speaking countries published in national peer-reviewed journals.

\section{Clinical implications}

While limited evidence of the efficacy of cancer helplines in supporting caregivers found in this review impedes evidencebased recommendation, the trials conducted may provide some guidance in improving health care delivery in the cancer population. There is a great need to support caregivers and health professionals can play a crucial role in identifying those in need by screening them for distress and potential unmet needs to allow triage to the most appropriate interventions for those who require support. Creating awareness of cancer helpline services among families affected by cancer is important but selfinitiated contacts are less likely to occur [65], therefore structured pathways may need to be established between primary health care providers and cancer helplines to enable telephone outcalls to families who may benefit from some extra help.

\section{Conclusion}

The majority of articles included in this review were descriptive in nature, making it difficult to draw any conclusions about the "true" benefits of helplines in changing caregiver health and well-being outcomes. Only two randomized controlled trials have been undertaken to date, both conducted in Australia, providing limited evidence on the efficacy of helpline services in improving the health and well-being of caregivers. More methodologically, sound intervention studies are needed internationally to strengthen the findings of the trials conducted so far. This will facilitate and guide the establishment of an evidence-based and structured cancer care triage and referral system in the future.

Acknowledgements We acknowledge Dr. Anna Ugalde for her advice on the conduct of systematic reviews.

\section{Compliance with ethical standards}

Conflict of interest The authors declare they have no conflict of interest.

Research involving human participants This research did not involve human participants.

Informed consent Since this research did not involve human participants, informed consent was not required.
Open Access This article is distributed under the terms of the Creative Commons Attribution 4.0 International License (http:// creativecommons.org/licenses/by/4.0/), which permits unrestricted use, distribution, and reproduction in any medium, provided you give appropriate credit to the original author(s) and the source, provide a link to the Creative Commons license, and indicate if changes were made.

\section{References}

1. Given BA, Given CW, Sherwood P (2012) The challenge of quality cancer care for family caregivers. Semin Oncol Nurs 28(4):205212

2. Hoberg D (2011) Patient satisfaction in the ambulatory oncology setting: are patients' needs being met? A descriptive study. Master thesis, University of Adelaide

3. Phillips JL, Curow DC (2010) Cancer as a chronic disease. Collegian 17:47-50

4. Salz T, Baxi S (2016) Moving survivorship care plans forward: focus on care coordination. Cancer Med 5(7):1717-1722

5. Van Ryn M, Sanders S, Kahn K, van Houtven C, Griffin JM, Martin M, Atienza AA, Phelan S, Finstad D, Rowland J (2011) Objective burden, resources, and other stressors among informal cancer caregivers: a hidden quality issue? Psycho-Oncology 20:44-52

6. Girgis A, Lambert SD, McElduff P, Bonevski B, Lecathelinais C, Boyes A, Stacey F (2013) Some things change, some things stay the same: a longitudinal analysis of cancer caregivers' unmet supportive care needs. Psycho-Oncology 22:1557-1564

7. Heckel L, Fennell KM, Reynolds J, Osborne RH, Chirgwin J, Botti M, Ashley DM, Livingston PM (2015) Unmet needs and depression among carers of people newly diagnosed with cancer. Eur J Cancer 51:2049-2057

8. Lambert SD, Girgis A, Lecathelinais C, Stacey F (2013) Walking a mile in their shoes: anxiety and depression among partners and caregivers of cancer survivors at 6 and 12 months post-diagnosis. Support Care Cancer 21:75-85

9. Sklenarova H, Krumpelmann A, Haun MW, Friederich H-C, Huber J, Thomas M, Winkler EC, Herzog W, Hartmann M (2015) When do we need to care about the caregiver? Supportive care needs, anxiety, and depression among informal caregivers of patients with cancer and cancer survivors. Cancer 121(9):1513-1519

10. Stenberg U, Ruland CM, Miaskowski C (2010) Review of the literature on the effects of caring for a patient with cancer. Psycho-Oncology 19:1013-1025

11. Northouse LL, Katapodi MC, Song L, Zhang L, Mood DW (2010) Interventions with family caregivers of cancer patients. MetaAnalysis of randomized trials. Ca Cancer J Clin 60:317-339

12. Waldron EA, Janke EA, Bechtel CF, Ramirez M, Cohen A (2013) A systematic review of psychosocial interventions to improve cancer caregiver quality of life. Psycho-Oncology 22(6):1200-1207

13. O'Toole MS, Zachariae R, Renna ME, Mennin DS, Applebaum A (2017) Cognitive behavioral therapies for informal caregivers of patients with cancer and cancer survivors: a systematic review and meta analysis. Psycho-Oncology 26(4):428-437

14. Kent EE, Rowland JH, Northouse L, Northouse L, Litzelman K, Chou W-YS, Shelburne N, Timura C, O’Mara A, Huss K (2016) Caring for caregivers and patients: research and clinical priorities for informal cancer caregiving. Cancer 122(13):1987-1995

15. Bright MA (2007) The national cancer institute's cancer information service: a premiere cancer information and education resource for the nation. J Cancer Educ 22(Suppl):S2-S7

16. Morra ME, Thomsen C, Vezina A, Akkerman D, Bright MA, Dickens C, Hill DJ, Jefford M (2007) The international cancer information service: a worldwide resource. J Cancer Educ 22(Suppl):S61-S69 
17. Chambers SK, Girgis A, Occhipinti S, Hutchison S, Turner J, Carter R, Dunn J (2009) Beating the blues after cancer: randomised controlled trial of a tele-based psychological intervention for high distress patients and carers. BMC Cancer 9:189

18. Cancer Council Australia (2018) Cancer Council 1311 20. https:// www.cancer.org.au/about-cancer/patient-support/131120.html. Accessed 16 Apr 2018

19. The Cancer Council New South Wales (2006) The cancer council New South Wales annual report: 1 October 2005 - 30 June. Cancer Council NSW, Sydney, p 2006

20. La Porta M, Hagood H, Kornfeld J, Treiman K (2007) Evaluating the NCI'S cancer information service contact centers: meeting and exceeding the expectations of the public. J Cancer Educ 22(Suppl): S18-S25

21. Clinton-McHarg T, Paul C, Boyes A, Rose S, Vallentine P, O'Brien L (2014) Do cancer helplines deliver benefits to people affected by cancer? A systematic review. Patient Educ Couns 97:302-309

22. Moher D, Liberati A, Tetzlaff J, Altman DG (2009) Preferred reporting items for systematic reviews and meta-analysis: the PRISMA statement. Ann Intern Med 151:264-269

23. Richardson WS, Wilson MC, Nishikawa J, Hayward RS (1995) The well-built clinical question: a key to evidence-based decisions. ACP J Club 123:A12-A13

24. Toma M, McAlister FA, Bialy L, Adams D, Vandermeer B, Armstrong PW (2006) Transition from meeting abstract to fulllength journal article for randomized controlled trials. JAMA 295(11):1281-1287

25. Higgins JPT, Green S (eds) (2011) Cochrane handbook for systematic reviews of interventions version 5.1.0 [updated March 2011]. The Cochrane Collaboration Available from www.cochranehandbook.org

26. Boltong A, Ledwick M, Babb K, Sutton C, Ugalde A (2017) Exploring the rationale, experience and impact of using cancer information and support (CIS) services: an international qualitative study. Support Care Cancer 25:1221-1228

27. Boudioni M, McPherson K, Mossman J, Boulton M, Jones AL, King J, Wilson E, Slevin ML (1999) An analysis of first-time enquirers to the cancer BACUP information service: variations with cancer site, demographic status and geographical location. Br J Cancer 79(1):183-145

28. Boudioni M, Mossman J, Boulton M, Hardy P (2004) Differences in enquiries to cancerBACUP information service by living arrangements. Eur J Cancer Care 13:6-10

29. Bright MA, Fleisher L, Thomsen C, Morra ME, Marcus A, Gehring W (2005) Exploring e-health usage and interest among cancer information service users: the need for personalized interactions and multiple channels remains. J Health Commun 10:35-52

30. Browman GP, Czukar D, Mohide EA, Neimanis M, De Pauw S, Tew M, Barrett B (1995) Survey of telephone contacts for a regional Canadian cancer society district. The Can J Oncol 5(4):420-426

31. Byrne MM, Kornfeld J, Vanderpool R, Belanger M (2012) Discussions of cancer clinical trials with the national cancer institute's cancer information service. J Health Commun 17:319-337

32. Chambers SK, Girgis A, Occhipinti S, Hutchison S, Turner J, Morris B, Dunn J (2012) Psychological distress and unmet supportive care needs in cancer patients and carers who contact cancer helplines. Eur J Cancer Care 21:213-223

33. Darrow SL, Speyer J, Marcus AC, Ter Maat J, Krome D (1998) Coping with cancer. The impact of the cancer information service on patients and significant others. Part 6. J Health Commun 3(suppl):86-96

34. Davis S, Stewart S, Bloom J (2004) Increasing the accuracy of perceived breast cancer risk. Results from a randomized trial with cancer information service callers. Prev Med 39:64-73

35. Davis SW, Fleisher L, Ter Maat J, Muha C, Laepke K (1998) Treatment and clinical trials decision making: the impact of the cancer information service. Part 5. J Health Commun 3(suppl:7185

36. Dean A, Scanlon K (2007) Telephone helpline to support people with breast cancer. Nurs Times 103(42):30-33

37. Ekberg K, McDermott J, Moynihan C, Brindle L, Little P, Leydon GM (2014) The role of helplines in cancer care: interwining emotional support with information or advice-seeking needs. J Psychosoc Oncol 32(3):359-381

38. Fennell KM, Heckel L, Wilson C, Byrnes M, Livingston PM (2016) How calls from carers, friends and family members of someone affected by cancer differ from those made by people diagnosed with cancer; analysis of 4 years of South Australian cancer council helpline data. Support Care Cancer 24:2611-2618

39. Freimuth VS (1993) Narrowing the cancer knowledge gab between whites and African Americans. J Natl Cancer Inst Monogr 14:8191

40. Hawkes AL, Hughes KL, Hutchison SD, Chambers SK (2010) Feasibility of brief psychological distress screening by a community-based telephone helpline for cancer patients and carers. BMC Cancer 10:14

41. Heckel L, Fennell KM, Mohebbi M, Byrnes M, Livingston PM (2017) Demographic characteristics, call details and psychosocial support needs of the family/friends of someone diagnosed with cancer who access Australian cancer council telephone information and support services. Eur J Oncol Nurs 28:86-91

42. Heidrich S, Ward S, Julesberg K, Miller N, Donovan H, Gunnarsdottir S, Davis S, Hughes S, Serlin RC (2003) Conducting intervention research through the cancer information service: a feasibility study. Oncol Nurs Forum 30(1):131-134

43. Hughes KL, Sargeant H, Hawkes AL (2011) Acceptability of the distress thermometer and problem list to community-based telephone cancer helpline operators, and to cancer patients and carers. BMC Cancer 11:46

44. Jefford M, Black C, Grogan S, Yeoman G, White V, Akkerman D (2005) Information and support needs of callers to the cancer helpline, the cancer council Victoria. Eur J Cancer Care 14:113-123

45. Klikovac T (2015) The first telephone line for the psychological support to oncological patients and their family members in Serbia. Srp Arh Celok Lek 143(11):726-730

46. Lechner L, DeVries H (1996) The Dutch cancer information helpline: experience and impact. Patient Educ Couns 28:149-157

47. Linehan K, Fennell KM, Hughes DL, Wilson CJ (2017) Use of the distress thermometer in a cancer helpline context: can it detect changes in distress, is it acceptable to nurses and callers, and do high scores lead to internal referrals? Eur J Oncol Nurs 25:49-55

48. Maibach EW, Davis SH, Ter Maat J, Rivera N (1998) Promoting cancer prevention and screening: the impact of the cancer information service. Part 7. J Health Commun 3(suppl):97-108

49. Manning DL, Quigley P (2002) Understanding the needs of people using a cancer information service in Northern Ireland. Eur J Cancer Care 11:139-142

50. Marcus AC, Bastani R, Reardon K, Karlins S, Prabhu Das I, Van Herle MP, McClatchey MW, Crane LA (1993) Proactive screening mammography counseling within the cancer information service: results from a randomized trial. J Natl Cancer Inst Monogr 14:119 129

51. Marcus AC, Garrett KM, Kulchak-Rahm A, Barnes D, Dortch W, Juno S (2002) Telephone counseling in psychosocial oncology: a report from the cancer information and counseling line. Patient Educ Couns 46:267-275

52. Meissner HI, Anderson DM, Odenkirchen JC (1990) Meeting information needs of significant others: use of the cancer information service. Patient Educ Couns 15:171-179

53. Morris BA, Thorndike FP, Ritterband LM, Glozier N, Dunn J, Chambers SK (2015) Sleep disturbance in cancer patients and 
caregivers who contact telephone-based help services. Support Care Cancer 23:1113-1120

54. Namboodiri KK, Fisher JB, Harris RE (1993) The Ohio cancer information service: technology transfer on clinical trials and other measures of cancer control. J Cancer Educ 8(3):227-237

55. Reiches NA, Kesselring Brant N (1982) The Ohio cancer information service: callers, inquiries, and responses. Public Health Rep 97(2):150-155

56. Reubsaet A, Lechner L, De Vries H (2006) The Dutch cancer information helpline: more critical patients after 10 years. Patient Educ Couns 63:215-222

57. Rimer BK, Catoe KE, Graves C, Burklow J, Anderson DM (1993) Older callers to the cancer information service. J Natl Cancer Inst Monogr 14:165-169

58. Finney Rutten LJ, Squiers L, Hesse B (2007) Cancer-related information sought by the general public: evidence from the national cancer institute's cancer information service, 2002-2003. J Cancer Educ 22:91-98

59. Salako O, Robert AA, Okunade KS, Olatunji A, Fakolade A, Isibor V, Falode D (2016) Utilization of cancer information system for breast cancer control in Lagos, Nigeria. Pan Afr Med J 24:323

60. Slevin ML, Terry Y, Hallett N, Jefferies S, Launder S, Plant R, Wax H, McElwain T (1988) BACUP - the first two years: evaluation of a national cancer information service. BMJ 297:669-672

61. Sanders Thompson VL, Cavazos-Rehg P, Tate KY, Gaier A (2008) Cancer information seeking among African Americans. J Cancer Educ 23:92-101

62. Vanderpool RC, Kornfeld J, Mills L, Byrne MM (2011) Rural-urban differences in discussions of cancer treatment clinical trials. Patient Educ Couns 85:e69-e74
63. Venn MJ, Darling E, Dickens C, Quine L, Rutter DR, Slevin ML (1996) The experience and impact of contacting a cancer information service. Eur J Cancer Care 5:38-42

64. Dewing Ward JA, Baum S, Ter Maat J, Thomsen CA, Maibach EW (1998) The value and impact of the cancer information service telephone service. Part 4. J Health Commun 3(suppl):50-70

65. Heckel L, Fennell KM, Reynolds J, boltong A, Botti M, Osborne RH, Mihalopoulos C, Chirgwin J, Williams M, Gaskin CJ, Ashley DM, Livingston PM (2018) Efficacy of a telephone outcall program to reduce caregiver burden among caregivers of cancer patients [PROTECT]: a randomised controlled trial. BMC Cancer 18(1):59

66. Heckel L, Fennell KM, Orellana L, Boltong A, Byrnes M, Livingston PM (2018) A telephone outcall program to support caregivers of people diagnosed with cancer: utility, changes in levels of distress, and unmet needs. Support Care Cancer 26(11): 3789-3799

67. Jefford M, Kirke B, Grogan S, Yeoman G, Boyes A (2005) Australia's cancer helpline. An audit of utility and caller profile. Aust Fam Physician 34(5):393-394

68. Sutherland G, White V (2005) Teaching moments in diet and nutrition for family and friends calling the cancer helpline. Aust N Z J Public Health 29(4):388-389

69. Chambers SK, Girgis A, Occhipinti S, Hutchison S, Turner J, McDowell M, Mihalopoulos C, Carter R, Dunn JC (2014) A randomized trial comparing two low-intensity psychological interventions for distressed patients with cancer and their caregivers. Oncol Nurs Forum 41(4):E256-E266

Publisher's note Springer Nature remains neutral with regard to jurisdictional claims in published maps and institutional affiliations. 